Indexed by

\title{
THE INFLUENCE OF THE COEFFICIENT OF VARIATION ON THE PROCESS RELIABILITY OF BRICK PRODUCTION
}

Crossref

KOBSON

\section{Ekaterina Gennadievna}

Pakhomova

Southwest State University,

Department of Industrial and

Civil Engineering, Kursk,

Russian Federation

\author{
Ksenia Olegovna Dubrakova \\ Southwest State University, \\ Department of Industrial and \\ Civil Engineering, Kursk, \\ Russian Federation
}

Viacheslav Yuryevich Aseev Southwest State University, Department of Industrial and Civil Engineering, Kursk, Russian Federation

Key words: brick masonry, variation coefficient, reliability

Cite article:

Pakhomova, E.G., Dubrakova, K.O., \& Aseev, V.Y. [2021]. The influence of the coefficient of variation on the process reliability of brick production. Journal of Applied Engineering Science, 19(2), 533 - 536. DOI:10.5937/jaes0-31737

Online aceess of full paper is available at: www.engineeringscience.rs/browse-issues 


\title{
THE INFLUENCE OF THE COEFFICIENT OF VARIATION ON THE PROCESS RELIABILITY OF BRICK PRODUCTION
}

\author{
Ekaterina Gennadievna Pakhomova, Ksenia Olegovna Dubrakova*, Viacheslav Yuryevich Aseev \\ Southwest State University, Department of Industrial and Civil Engineering, Kursk, Russian Federation
}

The goal of research was studying the influence of the variation coefficient values during statistical tests of building structures on the destruction probability and reliability of brick building structures. The article focuses on comparing the theoretical values of the probability theory problems with their practical application in building structures behavior calculation. The scientific novelty lies in the comparison of the calculated data according to the normal distribution with the practical values of the experiment carried out on brick structures. As a result, a dependence graph dependence of the reliability coefficient $k$ on the brick grade was, taking into account various coefficients of variation.

Key words: brick masonry, variation coefficient, reliability

\section{INTRODUCTION}

The general purpose of design, inspection, determination of the technical condition of building structures are diagnostics, identification of the physical wear and tear degree, the causes of defects and the reliability and safety factors determination. It is necessary to conduct a general and detailed structures examination, determine the physical and mechanical materials characteristics and conduct probabilistic statistical studies and calculations. In this regard, the study of the Influence of the variation coefficient on the building structures reliability is of scientific interest and practically an important research task.

Risk and reliability criteria are well known in many industrial sectors such as offshore, chemical or nuclear industries [1]. The most effective verification methods are based on advanced probabilistic approaches, including risk assessment methods taking into account the actual properties of the structure and the associated consequences of destruction. The subject study shows that advanced reliability approaches typically save 10$20 \%$ in structural materials and natural resource consumption [2-4]. In particular, data are presented on the relationship between cost (as the main factor influencing decision-making) and the reliability of the building structures investigated solutions, taking into account the impact on the environment [5-7]. Modeling methods that allow characterizing the uncertainty with a wide range of assumptions of dependences [8-10] have been developed, the analysis of the effect of partial safety factors on the reliability of design of steel elements [11] has been conducted Statistical methods allow to get at the design stage an idea of the reinforced concrete structures reliability under conditions of various beyond design impacts such as fire, formation and progressive development of fatigue cracks [12, 13]. At the same time, the theory of building structures reliability has a unified scientific justification, but the disadvantage of this justification is that the most important concept formulations do not contain the terms of structural mechanics, which can lead to in- accuracies in calculations and design [14-16].

\section{THEORY AND EXPERIMENTAL METHODS}

The normal (Gaussian) distribution is central to probabilistic statistical research. A continuous random variable $X$ is called normally distributed if its distribution density is:

$f(x)=\frac{1}{\sigma \cdot \sqrt{2 \pi}} \cdot e^{-\frac{(x-a)^{2}}{\sigma^{2}}}$

where a coincides with the mathematical expectation of the value $X:=M(X), \sigma$ parameter coincides with the root-sum-square deviation of the value $\mathrm{X}: \sigma=\sigma(\mathrm{X})$. The graph of the normal distribution function has the form of a dome-shaped curve, called the Gaussian, the maximum point has coordinates a. It means that this ordinate decreases with increasing value $\sigma$ (the curve is "compressed" relative to the axis of abscissae) and increases with decreasing value $\sigma$ (the curve "stretches" in the positive direction of the ordinate axis). Changing the values of the parameter a (with the same value $\sigma$ ) does not affect the shape of the curve, but only moves the curve along the vertical axis.

The normalized curve is used to solve problems of the probability theory, while in practice, this curve approximates the frequency distribution for a large number of observations for many variables with high accuracy. Consequently, in the absence of material restrictions on the number of objects and the time of the experiment, the statistical study is reduced to a normal curve. In this case, the percentage of products that withstand voltages tending to the average value depends on the coefficient of variation obtained during the tests, i.e. in fact, on the stability of the parameters of the raw materials and technologies used in the manufacture.

As an example, consider two materials with different coefficients of variation. Let us assume that $a_{1}=a_{2}, \sigma_{1}<\sigma_{2}$. Then determine the reliability of each materials. 
On the face of it, the answer appears obvious:

$R_{2}=a-3 \sigma_{2} \prec R_{1}=a-3 \sigma_{1}$

consequently, a structure made of the second material will have a larger section and, accordingly, will be more resistant to beyond design loads and influences.

The probability that the absolute value of the deviation will exceed three times the standard deviation for both functions is very small, namely $0.0027=1-0.9973$. It means that in only $0.27 \%$ of cases, this can happen. Such events, proceeding from the principle of the impossibility of unlikely events, can be considered practically impossible, but still possible.

Herewith, in the calculations various reliability factors are used, which take into account the probability of a random variable falling into the interval $[a-3 \sigma-c ; a-3 \sigma]$.

Consider the normal distribution function on the section $[-\infty ; a-3 \sigma-c]$. Let us determine the probability $P$ of the random variable falling value into the interval $[-\infty ; a-3 \sigma-c]$ :

$P=\Phi\left(t_{2}\right)-\Phi\left(t_{1}\right)$

Where $\Phi(t)$ is the Laplace function.

$t_{1}=\frac{-\infty-a}{\sigma}$

$t_{2}=\frac{a-3 \cdot \sigma-c}{\sigma}=-3+\frac{a-c}{\sigma}$

Taking into account expressions $(4,5)$, equation (3) will take the following form:

$P=\Phi\left(t_{2}\right)-\Phi\left(t_{1}\right)=-\Phi\left(\frac{-\infty-a}{\sigma}\right)+\Phi\left(\frac{a-c}{\sigma}-3\right)$

taking into account the oddness of the function $\Phi(t)$, expression (6) can be represented as:

$P=\Phi\left(t_{2}\right)-\Phi\left(t_{1}\right)=\Phi\left(\frac{\infty+a}{\sigma}\right)-\Phi\left(\frac{a-c}{\sigma}-3\right)=0,5-\Phi(C)$

The probability $P$ of the random variable falling value into the interval $[-\infty ; a-3 \sigma-c]$ directly depends on the value of the constant $\mathrm{C}$. Taking into account that the Laplace function is increasing, the following conclusion can be drawn: with increasing $\mathrm{C}, \mathrm{P}$ decreases. The value of the constant $C$ depends on the mathematical expectation, the statistically average deviation $\sigma$. In this case, the probability $\mathrm{P}$ depends only on $\sigma$. With an increase $\sigma$ (with an increase in the coefficient of variation), $P$ also increases. Given that the coefficient of variation $v$ and standard deviation $\sigma$ are directly proportional to each other-we can make the following conclusion: with an increase in $v$, the probability of the value of a random variable falling into the interval $[-\infty ; a-3 \sigma-c]$.

Let's consider the influence of the variation coefficient on reliability. Let's compare the values of the uniformity coefficient $\mathrm{K}$ with a variation of $10,13,17 \%$. We define reliability from the expression:

$P=1-V$

where $V=0,5-\Phi(t)$

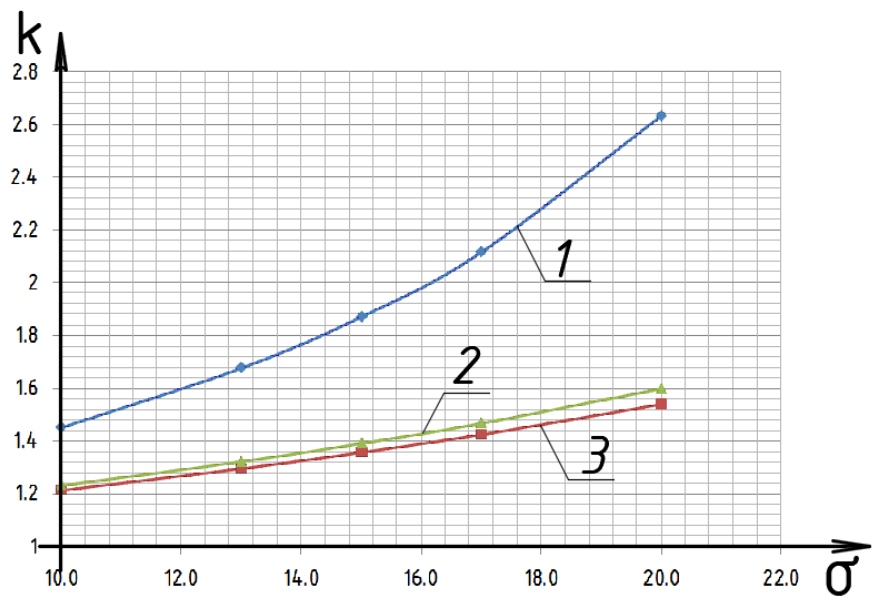

Figure 1: Graph of the dependence of the uniformity coefficient $k$ on the value of the coefficient of variation to ensure reliability: $1-V=0.999 ; 2-V=0.977 ; 3-V=0.96$

Table 1 - The value of the safety factor $k$ to ensure the reliability of $V$ at different variation coefficients $\sigma$

\begin{tabular}{|c|c|c|c|c|c|}
\hline \multirow{2}{*}{ Reliability, $v$} & \multicolumn{5}{|c|}{ Variation coefficient, $v$} \\
\cline { 2 - 6 } & $10 \%$ & $13 \%$ & $15 \%$ & $17 \%$ & $20 \%$ \\
\hline 0,999 & 1,449 & 1,675 & 1,869 & 2,114 & 2,632 \\
\hline 0,98 & 1,258 & 1,363 & 1,444 & 1,535 & 1,695 \\
\hline 0,977 & 1,230 & 1,321 & 1,389 & 1,466 & 1,597 \\
\hline 0,96 & 1,212 & 1,294 & 1,356 & 1,423 & 1,538 \\
\hline 0,95 & 1,198 & 1,273 & 1,329 & 1,389 & 1,493 \\
\hline
\end{tabular}

Therefore, with a coefficient of variation of $13 \%$, to ensure reliability 0.977 is required a uniformity coefficient of 1.35 . To analyze the dependencies (1-9) in Figure 1 and Table 1 , the dependence of the uniformity coefficient for ensuring reliability $V$ on the value of the variation coefficient is shown.

\section{EXPERIMENTAL SECTION}

Experimental studies of the influence of the brick grade on its reliability were carried out in the laboratory of Southwestern State University. For research, samples M100, M150, M200, M250 were selected. (72 pieces of each series).

The compressive and flexural strengths were determined in accordance with the current regulatory documents, and the value of the coefficient of variation was obtained. The results of experimental studies are presented graphically (see Fig. 2, 3).

As can be seen from the graph, the variation coefficient increases with increasing brick grade. Consequently, the reliability of the material is reduced.

\section{RESULTS AND DISCUSSION}

According to the results of analytical and experimental studies, it was determined that with an increase in the grade of brick, the heterogeneity of its strength characteristics increases. At the same time, an increase in the variation coefficient of the series obtained by measuring these 


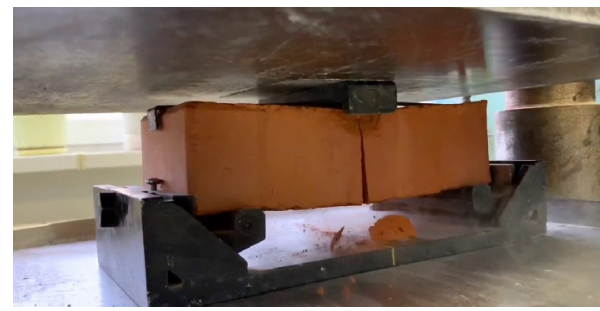

(a)

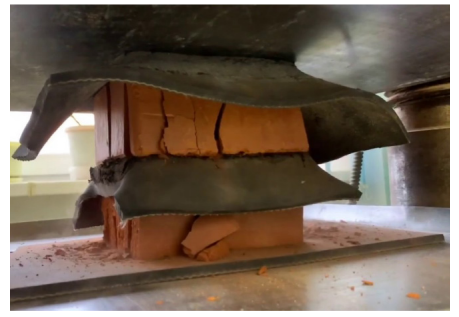

(b)

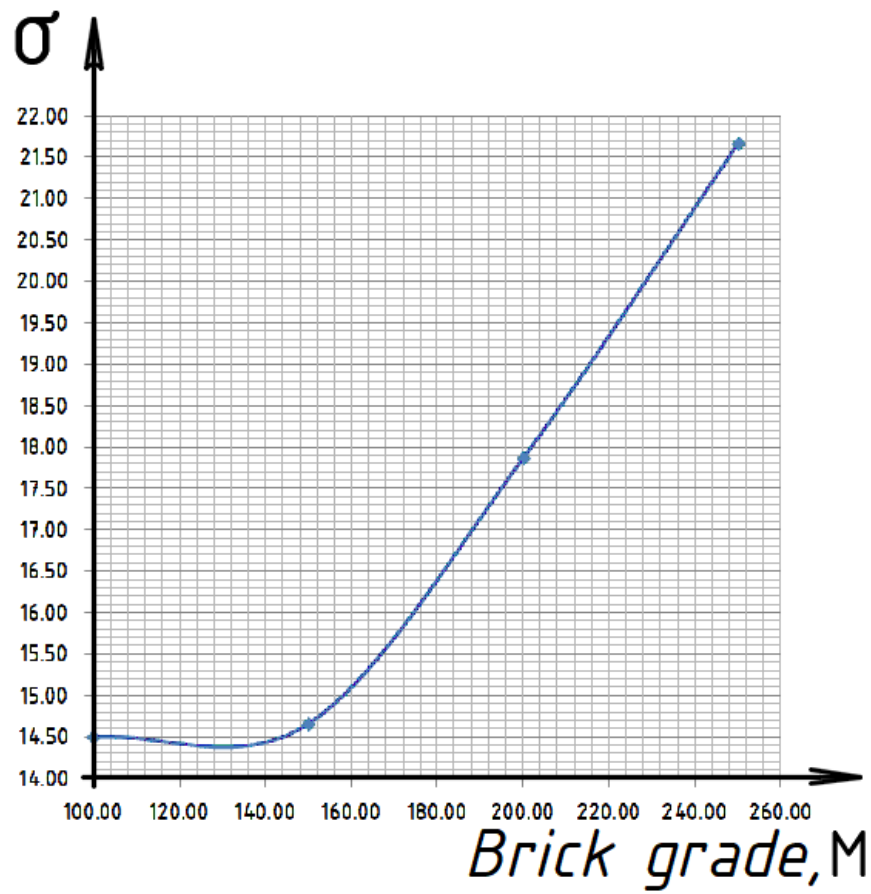

(c)

Figure 2: Carrying out (a) and the experimental studies results of the brick grade for reliability

characteristics reduces the reliability of building structures.

Hence, designing bearing systems made of bricks according to the ultimate and serviceability limit states, it is necessary to take into account the grade of the specified material when assigning the reliability coefficient

\section{CONCLUSIONS}

Producing high-strength bricks is more complicated both at the stages of preparation and extraction of raw materials and at the stages of drying and firing. Consequently, the likelihood of deviation of technical characteristics from the required average value with an increase in the grade of the specified material increases. Thereat, with an increase in the value of the coefficient of variation obtained during statistical tests of building structures,

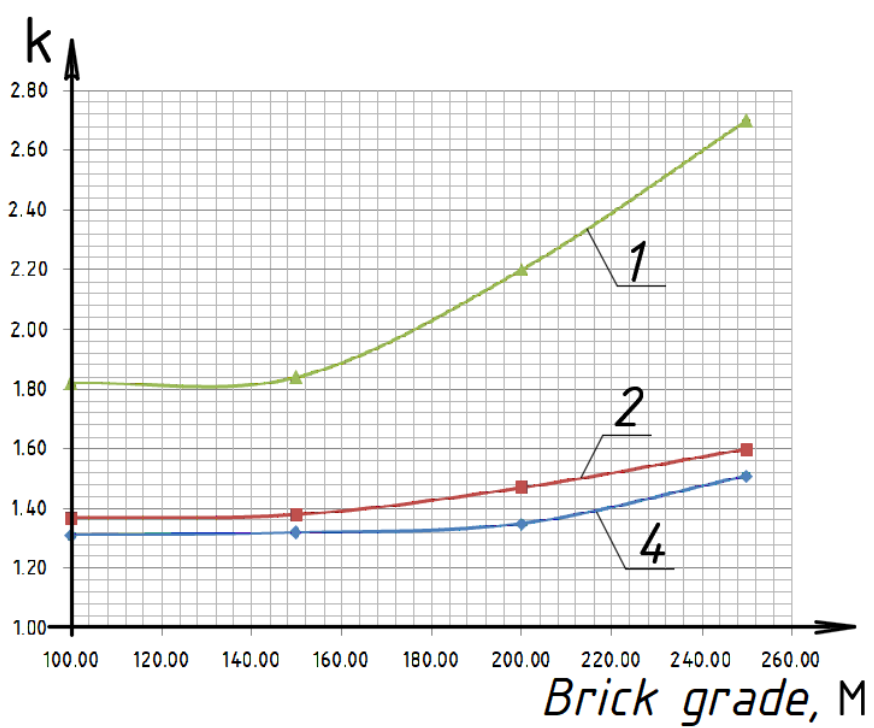

(a)

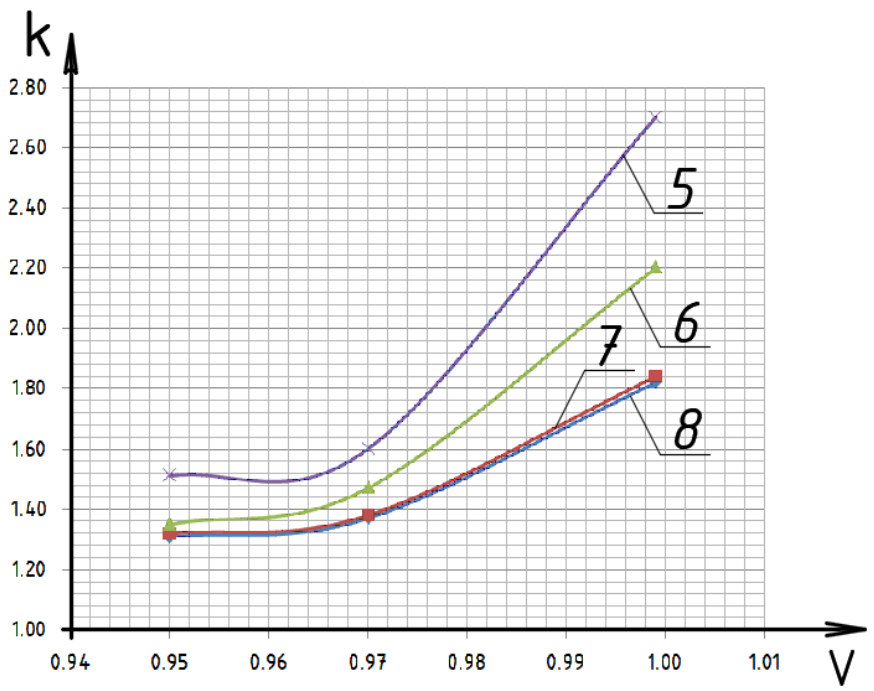

(b)

Figure 3: Dependence of the uniformity coefficient $k$ on the brick grade to ensure reliability (a): $1-V=0,999$; $2-V=0,977 ; 4-V=0,95$. Dependence of the uniformity coefficient for ensuring the reliability $V$ on the brick grade: 5-M250; 6-M200; 7-M150; 8-M100

increases the probability of destruction, which must be taken into account when designing or manufacturing.

In particular, when designing, because the coefficients of variation and homogeneity change depending on the strength characteristics of the brick, when determining the reliability factor, it is necessary to take into account the design grade of the specified material.

In production, you can take into account the increase in the coefficient of variation by changing the approach to brick standardization: for a material of higher strength, use a smaller interval for classification and vice versa. 


\section{REFERENCES}

1. Sýkora, M.; Holický, M.; Jung K.; Diamantidis, D. (2018). Project: Risk and reliability acceptance criteria for civil engineering structuresю. International Journal of Safety and Security Engineering, 8(2):287-298, DOI:10.2495/SAFE-V8-N2-287-298.

2. Holický M.; Sýkora M. Reliability. (2021). Approaches Affecting the Sustainability of Concrete Structures. Sustainability. Sustainability, 13(5), 2627; DOI: 10.3390/su13052627.

3. Yemelyanov S. G., E. G. Pakhomova, K. O. Dubrakova, S. V. Dubrakov. (2019). Stability of statically indefinite physically nonlinear timber structural systems). Journal of Applied Engineering Science, 17(3), 622, 404 - 407, DOI:10.5937/jaes17-21686.

4. Yemelyanov S. G., E. G. Pakhomova, K. O. Dubrakova. (2019). Reliability of RC frame-braced systems in dangerous geological conditions. Journal of Applied Engineering Science, 17(2), 602, 245 - 250, DOI:10.5937/jaes17-21685.

5. V.I. Travush, V.I. Kolchunov, K.O. Dmitrieva. (2016). Experimental and theoretical research of durabilities and stability the squeezed cores from wood at power and environmental. Proceedings of higher education institutions. Textile industry Technology, №3, 280-285.

6. Ženíšek, M.; Pešta, J.; Tipka, M.; Kočí, V.; Hájek, P. (2020). Optimization of RC Structures in Terms of Cost and Environmental Impact. Case Study. Sustainability, 12, DOI: 10.3390/su12208532.

7. Sakai, K.; Shibata, T.; Kasuga, A.; Nakamura, H. Sustainability design of concrete structures (2016). Struct. Concr., 17, 1114-1124, DOI:10.3390/ su13052627.

8. Webb, D.; Ayyub, B.M. (2017). Sustainability Quantification and Valuation I: Definitions, Metrics, and Valuations for Decision Making. ASCE-ASME J. Risk Uncertain. Eng. Syst. Part A Civ. Eng. , 3, DOI:10.1061/AJRUA6.0000893.
9. Z. Kala. (2015). Methods in Applications of Global Sensitivity Analysis Civil Engineering, In Proc. ESREL, Zürich (Switzerland), pp. 2541-2545 (2015), DOI:10.1051/matecconf/201710700004.

10. Králik J., Rosko P. (2017). Probabilistic and sensitivity analysis of Botlek Bridge structures. MATEC Web Conf. 10700004 DOI: 10.1051/matecco$\mathrm{nf} / 201710700004$.

11. Kala, Z. (2007). Influence of partial safety factors on design reliability of steel structures - probability and fuzzy probability assessments. Journal of Civil Engineering and Management, 13(4), 291-296. DOI: 10.3846/13923730.2007.9636449

12. Kosterin I.V., Muslakova S.V., Prisadkov V.I., Fadeev V.E. (2016). Reliability of concrete floor slabs under conditions of fire. Fire security, № 3. C. 94-97, DOI 10.25257/FE.2019.4.28-38

13. Krejsa M., Brozovsky J., Mikolasek D., Lehner P., Parenica P. (2017). Using DOProC method in reliability assessment of steel elements exposed to fatigue. MATEC Web Conf, 107 00046, DOI: 10.1051/ matecconf/201710700046.

14. Moiseenko R.P. (2016). Initial reliability of concrete elements. Structural mechanics and structure calculation. № 2 (265), 66-70, DOI:10.1088/1757899X/1021/1/012026.

15. Shmelev G.D., Ishkov A.N., Maleva N.A. (2019). Reliability, durability and service life of buildings and their structural components. Housing and communal infrastructure, № 2 (9), 9-16.

16. M Holický. (2013). Optimisation of the target reliability for temporary structures. Civ. Environ. 30, 87-96, DOI:10.1088/1757-899X/869/5/052054.

17. Holický, M.; Retief, J. V. (2005). Reliability assessment of alternative Eurocode and South African load combination schemes for structural design Inst. Civ. Eng., 1, 15-20, DOI:10.17159/2309-8775/2018/ v60n3a3. 